\title{
Local and systemic disorders \\ caused by the presence of foreign bodies in the oral cavity
}

\section{Choroby miejscowe i układowe \\ wywołane obecnością ciał obcych w jamie ustnej}

\author{
Natalia Domian ${ }^{\mathrm{A}, \mathrm{D}, \mathrm{F}}$, Irena Kasacka ${ }^{\mathrm{A}, \mathrm{E}, \mathrm{F}}$ \\ Department of Histology and Cytophysiology, Medical University of Bialystok, Białystok, Poland \\ A - research concept and design; $\mathrm{B}$ - collection and/or assembly of data; $\mathrm{C}$ - data analysis and interpretation; \\ $D$ - writing the article; $E$ - critical revision of the article; $F$ - final approval of article
}

\section{Address for correspondence \\ Irena Kasacka \\ E-mail: kasacka@umb.edu.pl braces}

\section{Funding sources}

none declared

\section{Conflict of interest}

none declared

Received on May 09, 2017

Revised on June 16, 2017

Accepted on June 28, 2017

\begin{abstract}
The oral cavity is the first part of the digestive and respiratory systems; it fulfills important vital functions. Its normal function is dependent on many factors, both internal and external. The oral mucosa is constantly exposedtotheinfluenceofexternalfactors. Inaddition, variousforeign bodiesaremoreoften placedinthemouth, for both therapeutic treatment and decoration. For example: oral piercing, braces, dental implants, amalgam fillings. All of these factors can adversely affect the function of the mucosa as well as the whole organism.

This paper is a review of recent literature and an analysis of the impact of selected foreign bodies on the oral cavity and the whole body, with particular attention paid to the risks associated with piercing. Studies clearly show that the presence of foreign bodies in the mouth contributes to the formation of many pathological conditions and diseases. They can be just local complications, but in some cases also general. Literature reports indicate that the presence of foreign bodies in the mouth can also lead to complications that have serious consequences to overall health. The presence of foreign bodies, particularly in the oral cavity can adversely affect its functioning and health of the entire system.
\end{abstract}

Key words: dental implants, oral mucosa, braces, dental amalgam, oral jewelry

Słowa kluczowe: implanty stomatologiczne, błona śluzowa jamy ustnej, aparat ortodontyczny, amalgamat dentystyczny, biżuteria w jamie ustnej

DOI

$10.17219 / \mathrm{dmp} / 75553$

Copyright

○ 2017 by Wroclaw Medical University

and Polish Dental Society

This is an article distributed under the terms of the

Creative Commons Attribution Non-Commercial License

(http://creativecommons.org/licenses/by-nc-nd/4.0/) 
The oral cavity is the first part of the digestive and respiratory systems; it fulfills important vital functions. Its normal function is dependent on many factors, both internal and external. ${ }^{1,2}$

Drinking boiling water, consuming alcohol, or breathing in tobacco smoke are notorious for causing irritation of the oral mucosa. The mucosa is constantly exposed to the influence of external factors. In addition, various foreign bodies are more often placed in the mouth, for both treatment and decoration. All of these factors can adversely affect the function of the mucosa as well as the rest of the digestive system. ${ }^{3}$

The main component of the liquid of the oral environment is saliva, fluid produced by large and small salivary glands. Saliva consists mostly of water; it makes up about 94-99.5\% of saliva. The rest of the ingredients of saliva are solids as well as organic and inorganic substances. Saliva fulfills a number of crucial functions such as digestion, caching, acting as an antibacterial agent, remineralizing teeth, cleaning, and repairing damaged tissues. Prolonged contact of the oral mucosa with foreign objects may impair its function and lead to major changes both within it and throughout the body. ${ }^{1}$

Body modifications present a significant risk factor for local and systemic complications. This paper is a review of recent literature and an analysis of the impact of selected foreign bodies on the oral cavity and the whole body, with particular attention paid to the risks associated with piercing.

\section{Mouth piercing}

Piercing the oral cavity has become very popular in recent years, especially amongst young people. Ornamentation is often placed on the tongue, lip, and cheek. Most young people decide to puncture their bodies in professional salons that specialize in body piercings. However, due to the high cost of such services, many people choose to perform such a procedure independently at home, or they ask an untrained person to perform it, which often results in contamination and multiple complications. ${ }^{4,5}$ Jewelry is generally made of metals like stainless steel or titanium, as well as materials such as nylon, teflon, rubber, acrylic. Most piercings worn in the mouth are in the form of a bar that terminates at both ends with a ball that is screwed on. ${ }^{6}$

\section{Local complications of oral piercings}

Piercing of the oral cavity is a surgical intervention in the soft tissues, essentially interrupting its permanence. If such a procedure is performed without knowledge of anatomy and without abiding by the practices of basic hygiene, it can lead to many serious complications. ${ }^{6}$

Local complications can include pain, swelling, bleeding, and local infection, among other things. They occur within the first $24 \mathrm{~h}$ after treatment and are directly re- lated to the interruption of tissues and by the presence of a foreign body in the mouth. Early complications can also include difficulty in speaking and eating disorders, reduced tongue mobility, damage to the mucosa, increased saliva secretion, and displacement of piercings into the tongue muscles. Nerve damage such as facial nerve, trigeminal, hypoglossal, glossopharyngeal also belong to the early complications of piercing. . $^{5}$

The effects of long-term use of piercings in the oral cavity also include damaged tooth enamel, cracking and spatter fragments thereof, which may lead to hypersensitivity and even inflammation of the tooth pulp. In current literature one can find evidence of recession and damage of the gums of people with piercings in their tongues. ${ }^{7}$

Speaking, eating, and fiddling with the piercing can cause it to hit the surface of the gums and palate, leading to irritation or mechanical damage of tissue. Gingival pockets become deeper, the neck of the tooth becomes exposed, and this can lead to the dislocation and even loss of the tooth. Such changes appear most frequently after 2 years of exposure to the piercing. ${ }^{5}$

Prolonged use of an oral piercing may also lead to the piercing being covered by the surrounding tissue. This happens if adornment barbells are too short and the nut pinches the place of piercing. On the other hand, barbells that are too long cause mucosal and tooth damage. Minor abrasions, infections, and inflammation can appear in places of contact of adornment with the epithelium of the oral cavity. ${ }^{8,9}$

Prolonged contact of tissues with piercings, which are the potential sources of ions of various metals released directly into the mouth, may cause side effects such as irritation, allergy, and other toxic effects. Irritation of tissue may lead to burning and tingling of the mouth, edema formation of shiny waxy gloss, exfoliating epithelium, formation of bubbles, and erythema. ${ }^{10}$

Scars and keloids may arise after an oral piercing. The constant movement of the piercing can lead to the formation of hypertrophic scars, and can cause changes in the structure of the tongue papillae. The literature reports pathological changes such as post-traumatic fibromas, congestive cysts, mucous cysts of the salivary glands, inflammatory fibrous hyperplasia, or tongue abscesses. ${ }^{11}$

A morphological and cytomorfometrical study performed by researchers at the Medical University of Bialystok ${ }^{12}$ showed changes in the epithelial cells of the oral cavity with piercings, expressed in less regular shapes of cells, disturbances in the size of the nucleus relative to the volume of the cytoplasm, and intensity of coloration of individual cellular elements.

\section{General complications of oral piercings}

Young people follow fashion trends, trying to please their peers, differentiate themselves, and in an effort to be "trendy" they often do not realize the dangers of such embellishing procedures. The improper treatment of an oral 
piercing, which seems to be a simple procedure, can lead to serious systemic disorders. Many reports indicate that it may have an impact on the general health of the patient.

The data that we found in our research indicates that frequent complications include infection by viruses: HIV, HSV, hepatitis (type A, B, C, D). These infections are most often caused by basic hygiene rules not being observed, which results from little to no awareness of the dangers on the part of the people who subject themselves to the procedure and the ones who perform the body modification. ${ }^{13}$

Complications associated with tongue piercing can be very serious, even life threatening. The tongue swells up immediately after the procedure and its volume is increased significantly, which can cause breathing problems. A piercing may impair the free movement of the tongue, making it difficult to pronounce certain sounds. ${ }^{11}$

During the procedure, bacteria and microbes may get into the bloodstream, it could cause endocarditis in extreme cases. A lack of swift treatment leads to damage or the destruction of the heart valves. ${ }^{14}$

Lakhan and Harle described the case of a patient with hepatitis that was caused by infection with Herpes simplex, which probably occurred during tongue piercing. ${ }^{15}$ The patient complained of pain and inflammation around the site of a recent tongue piercing 2 weeks prior to the appearance of the initial symptoms.

\section{Braces (fixed and mobile)}

Due to the increased emphasis on the aesthetics of the smile and overall appearance, the last decades recorded an increase of patients coming to the orthodontist. Over recent years, there has been a very rapid development of techniques for the treatment of fixed and mobile braces. The choice of brackets, wires, and additional elements is enormous. Metal brackets can be in silver, gold or coated with a special enameled tooth-color. Wire is located in brackets and secured with colored elastics ties. ${ }^{16}$

Removable appliances are used mainly for correcting teeth and bite abnormalities among children who still have mixed dentition (milk and permanent teeth). These braces are made of acrylic and metal elements (arches, springs, screws, clamps). In contrast, fixed appliances are used in patients with permanent dentition. ${ }^{16}$

\section{Local complications associated with the use of braces}

Alloys are frequently used for the manufacture of metal braces. Pure metals are not used. Brackets and arches are usually made from metal. Many different alloys are used, including cobalt alloy, nickel-chromium, stainless steel, $\beta$-titanium alloy and nickel-titanium. These alloys, in addition to $\beta$-titanium, contain significant amounts of nickel. This element can cause local or systemic allergic reactions. ${ }^{17}$
Because of the large quantity and variety of metals present in a patient's oral cavity during orthodontic treatment, a variety of biochemical reactions can occur. The release of metal ions from an orthodontic appliance takes place in the first stage of corrosion, and is dependent on many factors, such as general health, the amount of salivation, oral $\mathrm{pH}$, temperature, and properties of food intake. The potential difference of metal creates a galvanic cell in which the electrodes are metal braces: brackets, arches, rings. This can result in numerous disease lesions in the form of local symptoms that can include pain, gingival hyperplasia, a tendency to ulcers, recurrent aphthous ulcers, actinic white, and mucositis. ${ }^{17}$ Alloys containing potent allergenic metals such as nickel and titanium often cause reactions of a contact character. Contact allergy is a specific body's hypersensitivity induced by direct contact with allergenic substances. The spectrum of symptoms is very wide: an itching and burning sensation in the mouth, erythema, bullous lichenoid, swelling, erosions and ulcers. ${ }^{18}$

Orthodontic treatment significantly impedes the maintenance of proper oral hygiene. This is conducive to increased accumulation of plaque, which can lead to enamel demineralization around orthodontic appliance components. The deposition of plaque (biofilm) initiates the formation of dental caries. It was noted that changes such as caries can appear after 4 weeks from the start of orthodontic treatment. ${ }^{19,20}$

It has been shown that the presence of braces causes changes in the saliva and thus leads to disturbances in the oral environment. It was proven that patients with orthodontic appliances have higher concentrations of bacteria in the mouth, changes in the buffer capacity, $\mathrm{pH}$, and the speed of saliva secretion. Increasing the secretion of saliva and buffering capacity, as well as raising the $\mathrm{pH}$ in the environment increases the anti-caries properties of orthodontic appliances. On the other hand, it increases surface retention of plaque, which favors the growth of bacteria and the formation of gingivitis. ${ }^{19,21}$

A study by Kasacka et al. has shown significant changes in the morphology of epithelial cells of the oral mucosa of patients with braces. ${ }^{22}$ These changes were even more marked in patients with braces and amalgam fillings.

\section{Dental implants}

Implants are now being used more often in order to compensate for the loss of teeth. Implants are used by people who have lost their teeth due to periodontal disease, accidents or other reasons. Implantoprosthetic treatment allows for aesthetic and functional replacements of the missing teeth. Dental implants consist of 3 components: the implant post, abutment and crown. Implants are typically made of titanium or a titanium alloy coated with hydroxyapatite or titanium plasma spray (porous ceramic materials that are meant to stimulate ingrowths of live bone tissue). 
A prosthetic abutment (implant connector) is a backrest, a kind of nut connecting the implant to the crown of the tooth. Abutments are usually made of titanium. The crown of the tooth, the visible element of the implanted tooth replacement, is produced from ceramic materials. ${ }^{23}$

\section{Dental implants: Local complications}

Implants may end in failure, and this failure is not only associated with the loss of the implant or implants. It can also cause incurred financial losses or wasted time spent on treatment. The failure of a dental implant may lead to the deterioration of tissue and other complications. ${ }^{4}$

Increased pain during chewing may indicate that the implant has become loose, due to the growth of pathogenic bacteria and inflamed tissues perigraft. ${ }^{24}$

The soft tissue adjacent to the titanium implants is characterized by a weaker blood supply than tissues surrounding the natural teeth. This has an impact on their greater susceptibility to inflammatory processes and weakens the reaction of the immune system. ${ }^{25,26}$ Inflammatory, atrophic, and hyperplastic changes may be a consequence of disturbances in the integration of implants into intraosseous tissues. Most often, however, it leads to mucositis under the direct vicinity of the implant. Changes initiate the appearance of bacterial microflora, which is responsible for inflammation, and can also move to the bone tissue (periimplantitis). Research has shown the presence of bacteria: Gram-negative rods and spirochetes bacteria, Staphylococcus spp., Enterobacteriaceae spp. and fungi of the genus Candida spp. in inflamed tissues surrounding implants. ${ }^{26,27}$

Further research of the literature on the subject leads to the conclusion that in recent years there has been an increase of reports of hypersensitivity reactions to intraosseous titanium implants, which are used among others in dentistry. In general, these are local symptoms that appear on the face. Such symptoms may include swelling, erythema, or eczema. Some reports suggest that exposure of a part of the intraosseous implants, hyperplasia of the gums, as well as to loss of implants (without inflammatory response, congestion or error in surgical procedures) can occur as a result of hypersensitivity to titanium. ${ }^{18,28}$

\section{Dental implants: General complications}

Surgical interventions in the oral cavity, such as the implants, are associated with the risk of numerous complications, including systemic ones. The oral cavity is constantly colonized by aerobic and anaerobic microorganisms, and it is impossible to maintain the sterility of the surgical field during surgery. Infections such as mucositis and periimplantitis pose a risk of life-threatening complications as a consequence of bacteremia, especially in patients undergoing immunosuppressive therapy or with implanted heart valves. ${ }^{29}$
Systemic consequences of mucositis and periimplantitis may be caused by a high concentration of bacteria and their harmful effects on distant tissues and organs. An inflammatory reaction is caused by the activity of bacteria or products of their metabolism and lead to tissue damage. Products of the bacterial metabolism (skatole, mercaptans, hydrogen sulfide, indole, etc.) may pass through the attachment of gingival epithelium to connective tissue, impairing cell function and causing damage. Enzymes (collagenase, hyaluronidase) produced by multiple bacteria break down collagen and the basic substances of the connective tissue. The reduction of its cohesion facilitates the penetration of cytotoxic bacteria. This may induce or exacerbate many diseases such as inflammation of the iris and retina, rheumatoid arthritis, glomerulonephritis, endocarditis, and myocardial infarction..$^{30,31}$

The injection of bacteria into the lumen of blood vessels can occur when the mucoperisoteum flap is prepared for peeling during dental surgery, the grinding of bone, or through the extraction or drilling of bone. Bacteremia can develop as a result of this, which can then lead to very serious complications.

Infective endocarditis (IE) is one of the diseases associated with the inflammation of the mouth. This disease is caused by bacteria in the endocardial wall or on the heart valves. Development of inflammatory damage to the heart valves can cause many complications, such as heart failure, episodes of thrombotic disease, thromboembolism, and even death. ${ }^{32}$

\section{Dental materials: Amalgam fillings}

Amalgam is a mixture of mercury (which makes up 50\% of the amalgam) with silver, copper, tin, cadmium, and zinc. It is a substance used to fill dental cavities in premolars and molars. Because of its unsightly appearance, patients often choose to exchange the amalgam filling with composite, a treatment which is particularly dangerous due to the release of mercury. The results of research carried out, especially in the Center of Bialystok, indicate the effect of amalgam restorations on the morphology and function of cells found in the saliva of patients. ${ }^{1}$

\section{Local complications in patients with amalgam fillings}

Studies on the release of mercury from amalgam and its effects on the human body are very controversial. According to the American Dental Association, amalgam fillings cause no complications. Some reports indicate that hypersensitivity to mercury can occur in about $1 \%$ of the population. ${ }^{1}$ Other studies demonstrate allergic reactions and local reactions manifested pathological changes in the oral cavity in patients with amalgam fillings. It has 
been observed that the symptoms of hypersensitivity occur more often in people who have had these fillings for more than 5 years. In many studies, it has been shown that chewing gum or chewing hard foods increases the amount of mercury that is emitted. ${ }^{33}$ A significant increase in the concentration of mercury vapor in the breath of the patient occurred during the application and removal of dental amalgam. ${ }^{34}$

The presence of amalgam fillings may increase the concentrations of mercury in the treated and surrounding teeth, and can cause discoloration. Often, an adverse effect on the oral mucosa, which can be caused by a number of pathological changes, such as tattoos, discoloration, leukoplakia, lichen planus. ${ }^{35}$

\section{General complications in patients with amalgam fillings}

Dental amalgam is the subject of much dispute and debate concerning its safety. The toxic effects of mercury on living organisms have been known for a long time and it is believed that metal poisoning is a significant health problem. The mercury released from dental amalgams is accumulated in the organs, which can cause serious types of diseases. ${ }^{36,37}$

Mercury causes neurotoxic effects that damage the peripheral and central nervous system, because it easily overcomes the blood-brain barrier. There are reports that mercury released from dental amalgams can make its way into a mother's breast milk and can be toxic to her baby. Mercury compounds may cause disturbances in the hemostatic effect, which in turn affects the activity of the clotting factor and changes the structure of the fibrin formed. ${ }^{38}$

Neurological symptoms such as weakened reflexes, memory loss, paraesthesia, or tremors may be caused as a result of inhaled mercury vapor in persons exposed (dentist, patient, e.g. during the insertion and removal of amalgam fillings). ${ }^{39}$ There was no evidence, however, that mercury released from amalgam fillings caused neurological symptoms. ${ }^{40}$

Mercury is removed from the body using the excretory system. Therefore, the kidneys are the site of the largest accumulations of the metal and are the most exposed to its destructive effects. Mercury impairs the function of the nephrons by damaging them by the effects of free radicals and impaired membrane permeability. The result may be an impairment of the proper function of the kidneys. ${ }^{39}$

\section{Conclusions}

The oral cavity, the first section of the digestive and respiratory systems, plays a vital role in the functioning of the whole organism. Foreign objects such as piercings, braces, dental implants or amalgam fillings can impair its function, causing a number of complications.
Studies clearly show that the presence of foreign bodies in the mouth contributes to the formation of many pathological conditions and diseases. They can be just local complications, as evidenced by the change in the shape of oral epithelial cells, changing the volume ratio of the nucleus to the cytoplasm, and the increase in the number of migrant cells in saliva. Described changes are very often the allergic type, because the alloy used in the production of ornaments, dental braces, implants, and amalgams are metals, the release of which can sensitize and cause contact allergies. Literature reports indicate that the presence of foreign bodies in the mouth can also lead to complications that have serious consequences in respect to the overall health of people.

\section{References}

1. Łapińska J, Kasacka I. Removal of dental amalgam fillings and its influence on saliva morphological picture - case report. Adv Med Sci. 2011;56:119-122.

2. Kasacka I, Łapińska J. Salivary cells in patients with dental amalgam and composite resin material restorations - a morphological investigation. Pol J Environ Stud. 2010;19:1223-1227.

3. McParland $\mathrm{H}$, Warnakulasuriya S. Oral lichenoid contact lesions to mercury and dental amalgam - A review. J Biomed Biotechnol. 2012:589-569.

4. Friedrich L, Madrid C, Odman-Jaques M, Yersin B, Carnon PN. Complications of body piercing. Rev Med Suisse 2014;10:662-668.

5. Maspero C, Farronato G, Giannini L, Kairyte L, Pisani L, Galbiati G. The complication of oral piercing and the role of dentist in their prevention: a literature review. Stomatologija, 2014;16:118-124.

6. Plastargias I, Sakellari D. The consequences of tongue piercing on oral and periodontal tissues. ISRN Dent. 2014:876510. doi: $10.1155 / 2014 / 876510$

7. Peticolas T, Tilliss TS, Cross-Poline GN. Oral and perioral piercing: a unique form of self-expression. J Contemp Dent Pract. 2000;1:30-46.

8. Hennequin-Hoenderdos NL, Slot DE, Van der Weijden GA. The incidence of complications associated with lip and/or tongue piercings: a systematic review. Int J Dent Hyg. 2016;14:62-73.

9. Stead LR, Williams JV, Williams AC, Robinson CM. An investigation into the practice of tongue piercing in the South West of England. Br Dent J. 2006;200:103-107.

10. Ventä I, Lakoma A, Haahtela S, Peltola J, Ylipaavalniemi P, Turtola L. Oral piercings among first-year university students. Oral Surg Oral Med Oral Pathol Oral Radiol Endod. 2005;99:546-549.

11. Escudero-Castaño N, Perea-García MA, Campo-Trapero J. Oral and perioral piercing complications. Open Dent J. 2008;2:133.

12. Łapińska J, Kasacka I. Morphologic and cytomorphometric analysis of epithehlial cells in the saliva of patients with oral piercing. Pol $J$ Environ Stud. 2011;20:62-66.

13. Chimenos-Küstner E, Batlle-Travé I, Velásquez-Rengifo S, GarcíaCarabaño T, Viñals-Iglesias $\mathrm{H}$, Roselló-Llabrés X. Appearance and culture: oral pathology associated with certain "fashions" (tattoos, piercings, etc.). Med Oral. 2003;8:197-206.

14. Dubose CJ, Pratt JW. Victim of fashion: Endocarditis after oral piercing. Curr Surg. 2004;61:474-477.

15. Lakhan SE, Harle L. Fatal fulminant herpes simplex hepatitis secondary to tongue piercing in an immunocompetent adult: A case report. J Med Case Rep. 2008;2:356.

16. Barber BR, Dziegelewski PT, Chuka R, O'Connell D, Harris JR, Seikaly $\mathrm{H}$. Bone-impacted fibular free flap: Long-term dental implant success and complications compared to traditional fibular free tissue transfer. Head Neck 2016;38:E1783-1787.

17. Kalimo K, Mattila L, Kautiainen H. Nickel allergy and orthodontic treatment. J Eur Acad Dermatol Venereol. 2004;18:543-545.

18. Pigatto PD, Berti E, Spadari F, Bombeccari GP, Guzzi G. Exfoliative cheilitis associated with titanium dental implants and mercury amalgam. J Dermatol Case Rep. 2011;5:89-90. 
19. Abbate GM, et al. Periodontal health in teenagers treated with removable aligners and fixed orthodontic appliances. J Orofac Orthop. 2015;76:240-250.

20. Atassi F, Avartani F. Oral hygiene status among orthodonic patients. $J$ Contemp Dent Pract. 2010;11:E025-32.

21. Lara-Carrillo E, Montiel-Bastida NM, Sánchez-Pérez L, Alanís-Tavira J. Effect of orthodontic treatment on saliva, plaque and the levels of Streptococcus mutans and Lactobacillus. Med Oral Pathol Oral Cir Bucal. 2010;15:e924-929.

22. Kasacka I, Szarmach IJ, Buczko P, Tankiewicz-Kwedlo A, Łapińska J. Preliminary evaluation of morphological parameters of saliva in patients subjected to orthodontic treatment with amalgam restorations. Pol J Environ Stud. 2007;16:132-134.

23. Buser D, Sennerby L, De Bruyn H. Modern implant dentistry based on osseointegration: 50 years of progress, current trends and open questions. Periodontol. 2000. 2017;73:7-21.

24. Diago M, Lopez A, Pelayo J. Update in dental implant periapical surgery. Med Oral Patol Oral Cir Bucal. 2006;11:429-432.

25. Berglundh T, Lindhe J, Jonsson K, Ericsson I. The topography of the vascular systems in the periodontal and peri-implant tissues in the dog. J Clin Periodontol. 1994;21:189-193.

26. Safioti LM, Kotsakis GA, Pozhitkov AE, Chung WO, Daubert DM. Increased levels of dissolved titanium are associated with periimplantitis - A case-control study. J Periodontol. 2016;18:1-12.

27. Mombelli A. Microbiology and antimicrobial therapy of periimplantitis. Periodontol. 2000. 2002;28:177-189.

28. Egusa H, Ko N, Shimazu T, Yatani H. Suspected association of an allergic reaction with titanium dental implants: A clinical report. J Prosthet Dent. 2008;100:344-347.

29. Fang $G$, et al. Prosthetic valve endocarditis resulting from nosocomial bacteremia: A prospective, multicenter study. Ann Inter Med. 1993;119:560-567.

30. Arigbede AO, Babatope BO, Bamidele MK. Periodontitis and systemic diseases: A literature review. I Indian Soc Periodontol. 2012;16:487.

31. Krisanaprakornkit $S$, Kimball JR, Weinberg A, Darveau RP, Bainbridge BW, Dale BA. Inducible expression of human $\beta$-defensin 2 by Fusobacterium nucleatum in oral epithelial cells: Multiple signaling pathways and role of commensal bacteria in innate immunity and the epithelial barrier. Infect Immun. 2000;68:2907-2915.

32. Offenbacher S, Beck JD, Moss K. Results from the Periodontitis and Vascular Events (PAVE) Study: A pilot multicentered, randomized, controlled trial to study effects to periodontal therapy in a secondary prevention model of cardiovascular disease. J Periodontol. 2009;80:190-201.

33. Evrard L, Parent D. Oral allergies to dental materials. Bull Group Int Rech Sci Stomatol Odontol. 2009;49:14-18.

34. Reinhardt JW, Boyer DB, Svare CW, Frank CW, Cox RD, Gay DD. Exhaled mercury following removal and insertion of amalgam restorations. J Prosthet Dent. 1983;49:652-656.

35. Fardal O, Johannessen AC, Morken T. Gingivo-mucosal and cutaneous reactions to amalgam fillings. J Clin Periodontol. 2005;32:430-433.

36. Gelband $\mathrm{H}$. The science and politics of dental amalgam. Int J Technol Assess Health Care, 1998;14:123-134.

37. Moreau T, Loudenot V. Dental amalgam and multiple sclerosis: what is the connection? Presse Med. 1999;28:1378-1380.

38. Pawlicka H, Michalska M, Kozakiewicz M, Michalski Ł, Arkuszewski P. Evaluation of selected parameters of blood coagulation in rats following exposure to mercury released from amalgams. J Stomatol. 2007;60:156-161.

39. Moen B, Hollund B, Riise T. Neurological symptoms among dental assistants: A cross-sectional study. J Occup Med Toxicol. 2008;3:10.

40. Lauterbach $M$, et al. Neurological outcomes in children with and without amalgam-related mercury exposure: Seven years of longitudinal observations in a randomized trial. J Am Dent Assoc. 2008;139:138-145. 